\title{
A Review of Population and Economic Growth Nexus in Ethiopia
}

\author{
Bazezew Endalew Abegaz \\ College of Business and Economics, Department of Economics, \\ Mekdela Amba University, Tuluawilia, Ethiopia
}

\begin{abstract}
The issue of population growth and economic growth discourse receives the attention of many scholars over time. The first segment of this review examines some of the introductory issues related to the nature of population growth and economic dynamics, the next section presents some of the basic theoretical and empirical arguments on the nexus between the two, as a result, the reviewer investigated that there is no common consensus between whether population growth positively affects economic growth or the other way round, however, in most cases raped population growth negatively and significantly affects economic growth in least developing countries due to lack of technological progress, low education undermines human capital and then productivity at the margin, cultural rigidity, socio-economic inequalities, and lack of well -regulated capital markets, and external dominance are the most common problems, on the other hand other researchers and theoretical arguments revealed the positive impact of population on the economy. Therefore, the mere argument of the impact of population growth on economic growth is a misleading concept, unless there is a separate analyses or consideration of other issues which are internal and external to the problem. Accordingly, the issue of population growth should be included in the process of development planning, which is endogenous to the growth process.
\end{abstract}

Keywords: population growth, Malthusian theory, revisionist view, Vector Error Correction, age structure.

DOI: $10.7176 / \mathrm{JESD} / 12-11-03$

Publication date:June $30^{\text {th }} 2021$

\section{Introduction}

The issue of population growth and economic growth discourse receives the attention of many scholars over time. At the early $21^{\text {st }}$ century, the world population spread about six billion and increase continuously in recent times. In every year about 75 million people were added in the world population (Ahmad R, and Ahamad K., 2016). Thus, the first section of this assessment examines the introductory part of the relationship between population growth and economic growth, the next section discusses about the major theoretical frame works /paradigms with different empirical literatures along with possible critics on the overall methodological set up, which is conducted on the dynamic interaction of population growth and economic growth in different nations in general and the case of Ethiopia in particular. Finally, some concluding remarks and possible suggestions based on the assessment of written literatures was presented.

Accordingly, there are a number of scholars who have a pessimistic view on the relationship between population growth and economic growth, especially before the $1950_{\mathrm{s}}$ and $1960_{\mathrm{s} .}$. The probable reason was that of their primary attempt of considering population growth as an exogenous factor of growth phenomenon, classical economists attributed the negative effect of population pressure on per capita income growth to the idea that large population dilutes the amount of physical capital coupled with diminishing marginal returns (Birdsall., 1988). However, during the late 1980, researchers began to become less assertive on the negative impact of population growth towards growth and development and started to come up with their optimistic argument of the discourse between these two variables (population growth versus economic growth) throughout the rationale behind that controlling population growth is likely to help developing countries if some conditions are fulfilled. The central idea here is that the mere increase in population growth by itself is a problem, however, the very nature of artificial variables through a well designed institutional development from various aspect may shift the perception of population growth on growth and development This less pessimistic and less assertive view of population and economic growth linkage gained prominence in the 1980s and is usually referred to as the revisionist view.

Following such a contradiction, empirical results regarding population development debate are mixed and no empirical findings dominate one over the other view. But it is likely that considering the issue of population as a significant variable towards the ongoing development practice is very crucial and unquestionable. However, the case in Ethiopia seems mirror or reciprocal to this changing global view on population development debate. For example, the neglect of population growth as a policy issue is common to most (if not all) reports of the Ministry of Finance and Economic Development(MOFED), our neglect of population matters has not benefitted "statistical success" nor do we have meaning full efforts made to deal with the demographic challenges of the country (Hassen A., 2012), states that Ethiopia had never been revisited her population policy once written since 1993. According to the report revealed by UNPA, population growth is occurring in developing countries and it is these countries which are affected most by the growth. Accordingly, Ethiopian population is projected to be 174 million in 2050 to become the $9^{\text {th }}$ largest countries in terms of population growth in the world. By referring such a proportion, 
(Tsegaye T et al.,2011) examined the overall nature of Ethiopian population growth along with population policy and the associated economic growth. He emphasized that in Ethiopia there is the hypothesis or consensus that population growth would take care of itself if the government only focuses on economic growth and development. There was a belief that population growth problem will solve by itself if the government invest much in education, health and other development activities. That is, as he assured, economic growth and development will solve the problem do not worry about it.

The important thing here is that raising the issue of population growth was erroneously considered as distribution of contraceptives and introducing of population control programs, since family planning is a private matter, population issue was considered as sensitive, this was a wrong understanding of the issue, in the sense that speaking about population growth or pressure means speaking about the type of population that is increasing, its size and the speed at which it is increasing. What an interesting thing about Tsegaye's outlook on this area was that many researchers conducted their analysis on the impact of population growth on the environment, as a case to land fragmentation and change in livelihood strategies, as he revealed they was forgotten or glossed over when finding solutions and recommendations of population as a factor. For instance, in the case of land tenure system, while the population factor is admitted as the driving force behind fragmentation, the solution to further fragmentation is sought on ways of securing the tenure systems such as privatization of land. The implication is that those researchers were finding solutions to the symptoms, not to the root cause of the problem; there was a tendency to see the rural households as static.

\section{Review of Literature}

The relationship between population growth and economic growth is a very controversial issue over time and scholars introduce their own argument towards whether population growth has a positive or negative implication on once economy or not, and they also argue on the idea that whether population growth is a cause of economic growth or it is caused by it. Therefore, Robert Malthus developed his argument which states that a large number of population growth is detrimental to the economy of the nation due to a variety of problems caused by the growth. He examined that population tends to grow geometrically, but food supply grow only in an arithmetic manner. According to his model, the causation goes in both directions. When there is high economic growth, it stimulates early marriage causes high birth rate leads to high population growth from which its growth is not compatible with the existing resource of the nation.

On the other hand, high population harms the economic growth of the nation because of its diminishing returns to production. This dynamic interaction between population and economic growth is the major standing point of the Malthusian model (Thuku et al., 2013). The Malthusian theory concludes that a higher population growth is associated with food problem, malnutrition and hanger, but there is a counter argument that the Malthusian theory works only when there is some provident assumptions (eg, no technological advancement), that is, if a nations has abundant natural and physical resource, well developed economic, social, political and institutional set up, the increase in its population is a negligible issue. Because it fosters the economy in an efficient manner through economies of scale of absorbing the surplus labor force in the economy (Bloom and Freeman., 1998), they state that food problem is more of a problem of poverty and inadequate income than a matter of population growth. The problem of food and population growth can be solved when income is enough to buy adequate food as prices provide adequate incentives to produce. In addition, developing economies would have to export more, receives foreign aid or borrow overseas to meet their increased demand for food by increasing imports.

Moreover, the classical view of population was challenged by Easter Boserup (1965) through her proposition that we would never out strip out food supply because technology and innovation will create new way of production system through cultivating the intensive margin of the land and it helps to intensify the possibility of higher supply, since population increment is considered as a pushing factor to further technological innovation. Implies that population is the autonomous force of exogenous factors which causes to technological progress in the agriculture and postulates that aggregate agricultural production function in the long run will always shift upwards in response to population pressure to maintain output per capita though there may be diminishing returns to the agricultural labor in the short run. Thus, primitive communities with a sustained population have a better chance of getting in to a process of genuine economic development than those who has a stagnant or declining community.

Despite the two prominent opposite arguments on the directional impact of population growth on the economy, there is also the neutralist point of view, who suggests that there is no significant correlation between population growth and economic growth rather there are factors that affect the impact of population growth on the economy, hence, as long as population pressure retards the economy of a nation in a given period of time, the effect might be reverse, if there is significant improvement in development policies and strategies towards bolstering infrastructural quality and related social and cultural development services like, education, health and other qualitative variables to economize the increased population pressure (Bloom et al., 2001).

The neutralist argument is somewhat makes sense from the ground that not only the mechanistic sense of 
considering population pressure has an impact on the economy, but also it is advisable to take in to account other factors that affect the dynamic nature of population growth and the economy, in other words, the economy of developed countries like economic growth has been accompanied by moderate population growth, this in turn helps them to spend more on education, health, quality of life of their people, employment opportunity and other development related attributes, this is the result of their well- defined policy and strategy from various circumstances, however, in developing countries population growth and economic growth is imbalance due to improper policy formulations, this results over population causes environmental degradation, unemployment, low quality labor force, political instability, civil war and insecurity consequently underdevelopment will emerge(Todaroo M., 1994).

According to the latest empirical research, the potential negative effect of population growth for economic growth and development can be divided in to several categories (Todaroo M., 1994): its impact on economic growth, poverty and inequality, health, education, food and the environment as well as international migration.

1. Economic growth: Evidences shows that although it is not the culprit behind economic stagnation, rapid population growth lowers per capita income growth in most developing countries, especially those that are already poor, dependent on agriculture, and experiencing pressure on land and natural resource.

2. Poverty and Inequality: Although aggregate statistical correlation between measures of poverty and population growth at the national level are often inconclusive, at the household level the evidence is strong and compelling. The negative consequence of rapid population growth fall most heavily on the poor because they are the once who are made land less, suffer first cuts in government health and education programs, and bear the brunt of environmental damage. Poor women once again bear the greatest burden of government austerity programs and another vicious cycle ensues. To the extent that large families perpetuate poverty, they also exacerbate inequality. 3. Education: Although the data are sometimes ambiguous on this point it is generally agreed that large family size and low incomes restrict the opportunities of patents to educate children. At the national level, rapped population growth causes educational expenditure to be spread more thinly, lowering quality for the sake of quantity, this in turn feeds back on economic growth because the stock of human capital is reduced by rapid population growth. 4. Health: High fertility harms the health of mother and children. It increases the health risks of pregnancy, and closely spaced berths have been shown to reduce birth weight and increase child mortality rates.

5. Food: Feeding the world's population is made more difficult by rapid population growth, a large fraction of developing country food requirements are the result of population increases. New technologies of production must be introduced more rapidly, as the best lands are already cultivated. International food relief programs become more widespread.

6. Environment: Rapid population growth contributes to environmental degradation in the form of forest encroachment, deforestation fuel wood depletion, soil erosion, declining fish and animal stocks, inadequate and unsafe water, pollution and urban congestion.

7. International Migration: Many observers consider the increase in international migration, both legal and illegal, to be one of the major consequences of developing countries population growth.

Consequently, post-Malthusian theorists criticized the Malthusian theory of population from the ground that the simplistic assumptions of Malthus do not stand the test of empirical verification. First the model ignores the enormous impact of technological progress in offsetting the growth inhabiting forces of rapid population increases. The second basic critics of the theory focused on its assumption that national rates of population increase are directly (positively) related to the level of national per capita income. According to this assumption, at relatively low level of per capita income, we should expect to find population growth rates increasing with increasing per capital income. But research indicates that there appears to be no clear correlation between population growth rate and levels of per capita income. As a result of modern medicine and public health programs, death rates have fallen rapidly and have become less dependent on the level of per capita income. Moreover, birth rates seem to show no rigid relationship with per capita income levels. Fertility rates vary widely for countries with the same per capita income, especially below $\$ 1000$. It is not so much the aggregate level of per capital income that matters for population growth, but rather how that income is distributed. It is the level of household income, not the level of per capita income that seems to matter most. In general, Malthusian and neo-Malthusian theories as applied to contemporary developed nations have severely limited relevance for the following reasons:

$\checkmark \quad$ They do not take adequate account of the role and impact of technological progress.

$\checkmark$ They are based on a hypothesis about a macro relationship between population growth and levels of per capita income that does not stand up to empirical testing of the modern period.

$\checkmark \quad$ They focus on wrong variable, per capital income, as the principal determinant of population growth rates. A much better and more valid approach to the question of population and development centers on the microeconomics of family size decision making in which, individual and not aggregate levels of living become the principal determinant of families' decision to have more or fewer children. Todaroo M.,1994) population growth is not a real problem, and justifies the following lines of argument.

- "The problem is not population growth but other issues. 
- Population growth is a false issue deliberately created by dominant rich country

agencies and institutions to keep developing countries in their dependent condition.

- For many developing countries and regions, population growth is in fact desirable.

Other Issues: Many observers from both rich and poor nations argue that the real problem is not population growth per se but one or all of the following four issues.

1. Underdevelopment. If correct strategies are pursued and lead to higher levels of living, greater selfesteem, and expanded freedom, population will take care of itself. Eventually, it will disappear as a problem, as it has in all of the present economically advanced nations. According to this argument, underdevelopment is the real problem, and development should be the only goal. With it will come to economic progress and social mechanisms that will more or less automatically regulate population growth and distribution. As long as people in developing countries remain impoverished, uneducated, and unhealthy and the social safety net remains weak, the large family will constitute the only real source of social security (i.e., parents will continue to be denied the freedom to choose a small family if they so desire). Some proponents of the underdevelopment argument then conclude that birth control programs will surely fail, as they have in the past, when there is no motivation on the part of poor families to limit their size.

2. World Resource Depletion and Environmental Destruction. Population can only be an economic problem in relation to the availability and utilization of scarce natural and material resources. The fact is that developed countries, with less than one-quarter of the world's population, consume almost $80 \%$ of the world's resources. In terms of the depletion of the world's limited resources, therefore, the addition of another child in the developed countries is as significant as the birth of many times as many additional children in the underdeveloped countries. According to this argument, developed nations should curtail their excessively high consumption standards instead of asking less developed nations to restrict their population growth. The latter's high fertility is really due to their low levels of living, which are in turn largely the result of the overconsumption of the world's scarce resources by rich nations. This combination of rising affluence and extravagant consumption habits in rich countries and among rich people in poor countries, and not population growth, should be the major world concern.

3. Population Distribution. According to this third argument, it is not the number of people per se that is causing population problems but their distribution in space. Many regions of the world (e.g., parts of sub-Saharan Africa) and many regions within countries (e.g., the northeastern and Amazon regions of Brazil) are viewed as under populated in terms of available or potential resources. Others simply have too many people concentrated in too small an area (e.g., central Java or most urban concentrations). Governments should therefore strive not to moderate the rate of population growth but rather to bring about a more natural spatial distribution of the population in terms of available land and other productive resources.

4. Subordination of Women. Perhaps most important, as noted previously, women often bear the disproportionate burdens of poverty, poor education, and limited social mobility. In many cases, their inferior roles, low status, and restricted access to birth control are manifested in their high fertility. According to this argument, population growth is a natural outcome of women's lack of economic opportunity. If women's health, education, and economic well-being are improved along with their role and status in both the family and the community, this empowerment of women will inevitably lead to smaller families and lower population growth".

Therefore, having discussed the major theoretical framework about the relationship between population growth and economic growth, it is better to see the various empirical investigations about the above scenario. Some researchers have argued that high fertility and rapid population growth promotes growth and development. Most recent studies have found that population growth has an ambiguous effect on economic development. Most of the time, the debate has focused on the effect of population size on economic growth with little attention given to the age structure of the population. In the mid to late $20^{\text {th }}$ century, the East Asian countries such as Hong Kong, Singapore, South Korea and Taiwan experienced rapid rates of economic growth taking part in what is known as the Asian Miracles. A closer examination of the Asian Miracle highlighted the very important role played by demographic factors in particular, changes in age composition and that of dependency ratio that were brought about by fast or significant decline in fertility rate. As a result, such a distribution in population across different age groups can have a significant impact on economic progress of a given nation (Zelalem, 2016)

Analogously, while population growth has a large negative effect on per capita income growth, this effect is counteracted by large positive effect from growth in the share of the population who are economically active. That is, the effect of population growth on economic development depends largely on the proportion of the working age and the policy mixes used to encourage people to work, save and investment, if the nature of the age structure is constant, therefore, the effect of population growth is neutral, however, as the proportion of workers rises or declines, so do opportunities for economic growth (Admasu T., 2015), according to his analyses, the mere 
argument / justification of the impact of population growth on economic growth is a misleading concept, unless there is a separate analyses undertaken from the demographic nature of population (age structure, dependency, economically active/working age group etc.) so as to address the problem easily as well as finding the relevant solutions, this analyses is consistent with the findings of (Hassen A.,2012), who employed the Vector Error Correction Model (VECM) to analyze the effect of population growth or demographic change on the Ethiopian economy focusing on the heterogeneous impact of demographic characteristics of population like, dependency ratio, working age group and the like.

So that, the study found out that the mere increase in the working aged population relative to others do not guarantee for earning the demographic dividend in the absence of proper policy mixes. If an increase in the working age proportion is not matched by increased job opportunities, they will face costly penalties, such as rising unemployment and may also higher crime and political instability. Admasu, also investigated the characteristics of east Asian regions and Japan as a case study, under his analysis, hence, for those countries, reputing the demographic divided appears to depend on several factors; strong public health systems that improve chilled survival and health in general; widespread availability and social acceptability of family planning, rapid and steady declines in chilled bearing ; improvement in educational enrolment and quality; and stable economic conditions conducive for growth and job creation.

On the other hand, rigid labor market regulations, level of investment in human capital, socio-economic inequalities, and lack of well -regulated capital markets are some of the constraints that limit the ability of developing countries such as Latin America, Middle East, and North Africa to benefit from population age structure.

The empirical findings of (Ali S et al., 2013) revealed that population growth have positive impact on economic growth and it is in line with the argument that population growth is not a real problem, population growth may help economic growth with large scale of labor force available and division of labor. To measure the effect of government policy and strategy on the relationship between the two variables, this study incorporates expenditure on health and education for development policy and unemployment for government efficiency and management as a proxy variable. The main rationale behind the inclusion of such proxy is to clarify the impact of population pressure on economic development. Because most of developing countries blamed population growth for their underdevelopment not considered their inherent problem for it, and hence, it concludes that population growth by itself is not a problem of growth and development strategy, poor institutions in creating the required availability of human resource and infrastructural development are the major problem. Martin, (2009) rapid population growth tends to depress saving per capita and retards growth of physical capital per worker.

Population growth is likely to intensify the foreign exchange constraints by placing more pressure on the balance of payment. The possibility of increasing food supply will require the improvement of new industries and technologies for export expansion and food import substitution. The dramatic increase in school age population and the expanding number of the labor force entrants puts every greater pressure on educational and training facilities and retards improvement in the quality of education, which is a real problem in developing economy.

Moreover, too dense the population pressure aggravates the problem of improving the health of the population and increase pressure on employment and the amount of investment available per labor market entrant. Therefore, population growth should be balance that of the growth of the economy, otherwise, the difficulty of the vicious cycle of underdevelopment continues significantly overtime.

According to the findings of Kassahun (2014), who employed the standard neoclassical growth model to investigate the impact of population growth on Ethiopian economy, which examines that it is possible to attain economic growth if we effectively allocate one or more of the factors of production, for instance, labor in terms of quantity and quality through population growth and education, increase in capital through adoption of technologies and economies of scale (Todaroo M.,1994). Hence the result of his analyses was that in the short run, there is a negative correlation between population growth and economic growth, whereas in the long run, population pressure intensifies economic growth.

Similarly, (Nwosu C et al., 2014), utilized a linear model of time sires data analyses along with relevant estimation mechanism of Augmented Dickey Fuller, Grander Causality, and Co- integration test, as a result, the study revealed that there was a significant positive relationship between population pressure and economic growth in the long run. And the study also emphasized about the unidirectional nature of population growth granger cause of economic growth or population growth induces economic growth. In contrary, the research conducted in Pakistan about the impact of population growth from (1981-2010) revealed that population negatively affects economic growth of Pakistan and crates lots of problems adding more in unemployed population of the country, malnutrition, retards educational quality, and natural resource depletion. Thus, the analyses in Pakistan seems consistent with the Malthusian scenario, which argues population pressure results in food shortage arises from the geometric nature of population growth relative to the arithmetic increment of food supply, which is the central point of the Malthusian model of population growth and the economy, who criticized by his ignorance of the "population pushing" factor of technological progress, economies of scale and in turn economic development 
(Simon J., 1977). The basic idea proposed by Julian Simon here is that the greater the total population the greater per capita income.

Thuku G., et al., (2013) examined the effect of population change in Kenya by using Granger-Causality and Vector Auto Regression (VAR) technique. Hence, the result of the study shows the existence of bi-directional causality between both population growth and economic growth in Kenya. Implies population growth has a positive impact on the overall economy of Kenya both in the short run and in the long run and the vice versa is true. This finding is highly consistent with or support the population driving economic growth hypothesis, which states that population growth in a given country promotes its economic growth and development.

An economic wide prediction function was used to verify the impact of population growth on income per capita as well as economic growth in the transition to steady state. They revealed out that an increase in the population growth rate of $10 \%$, would reduce per capita income in the steady state by $5 \%$ or half, if however, one considered human capital to be an additional factor of production, then the negative impact of population growth is larger as population growth now forces economies to use their scarce savings to equip young people with physical and human capital. As a result, a 1\% increase in population growth would decrease per capita income by $2 \%$ or double (Mankiw et al., 1992), which seems contradict to the argument behind endogenous growth model of inclusion of human capital and physical capital as the major catalysts of growth, even population increases.

In every poor country such as Cote d ivoir, Democratic republic of Congo, Ethiopia, Kenya, Madagascar, Nigeria, Pakistan, Sudan, Uganda, Tanzania, and Yemen agriculture still accounts for a significant part of the overall economy and it continues to be very hard to increase agricultural productivity at rates that are faster than population growth. In addition, rapid population growth adds to environmental degradation such as soil erosion, water pollution, and deforestation which in turn almost always has a negative impact of the wellbeing of poor people living in rural areas. The result of the study shows that the effect of population growth on per capita income growth linear and everywhere negative. Since a decline in fertility affects the age structure of the population in developing countries, it is found to have no significant statistical impact on economic growth when both the young age and old dependency ratios are included in the model. The effect of the old dependency ratio on per capita income GDP is always negative (Quang M., 2012).

Yaoanudjo E (2015) utilized the Auto Regressive Distributed Lag Model (ARDLM) approach of estimation technique to the economy of Ghana and reveals an inverse relationship between population growth and the economy in the short run and long run estimation. The study further explores that population density and labor force affects positively, whereas unemployment rate impacts negatively in the long run, but gross capital formation or investment was not statistically significant. The error correction term ecm (-1) result reveals a high speed of $83.6 \%$ of long run equilibrium adjustment every year after a long run shock in the model.

As the findings of (Tartiyus E et al., 2015) examined that there was a positive relationship between population growth and economic growth in Nigeria compared to the experience of advanced countries. For instance, China has the largest population, and its trend of economic growth has recently rendered the earlier views of more population less economic growth fallacious. The experience of China has allayed the fears of countries with high population growth rates in Nigeria. Consideration of economic growth must be holistic and comprehensive, to think that our world has unlimited resource is unrealistic. However, population growth in the case of Nigeria is a factor that perpetuates the rate of economic growth as evident in the result of the analyses obtained from this study.

Economic-demographic interrelationships are the basis of Africa's problem of underdevelopment and the retardation of the demographic transition. Buttressing the demographic and economic forces and ensuring their resistance has been the advantageous results of socio-cultural and traditional factors. The interaction of socio cultural and demographic forces has been the major correlate of deteriorating general conditions of living and worsening poverty and malnutrition, despite the effort of the national and international community's (Ohadike P., 1996). Recent research indicates that during the 1980s population growth on average, acted as a break on economic growth as measured by the growth rate of per capita GDP. This is a standard measure of a nation's total output of goods and services by residents and domestic businesses, excluding net income. (Ozgur et al., 2009) investigated the relation between population and per capita economic growth in Turkey and reveals a positive result between per capita income and population pressure.

The empirical findings of Bucci (2003) revealed the existence of long run relationship between population (size and growth) and economic growth focusing on human and physical capital as reproducible inputs. It shows that population growth has a negative effect on economic growth. But, population growth sometimes has a natural effect on economic growth, when individuals endogenously choose how much to save. This study also considered the combined effect of both physical and human capitals in the production of new human capital. If the two categories of capital can be substituted each other, in the education sector, the effect of population pressure on the economy is always negative, however, if they are complementary each other, the effect of population growth on per capita income growth becomes positive. It means that for a fixed amount of per capita physical capital stock, an increase in population results the entire or aggregate physical capital to rise. If physical and human capital are substituted each other, the larger amount of physical capital available in the economy deter the demand and supply 
of human capital, the increase of population size along with the reduction in human capital retarders the economy and the converse is also true.

(Furuoka F, 2010) investigated the existence of positive relationship between population growth and economic growth. The result of the analyses point out the unidirectional causality from economic development to population growth and conclude that economic development induces population growth. This is inconsistent with the findings of (Nwosu C et al., 2014), who revealed the conclusion that population growth, is granger cause of economic growth or population growth induces economic growth. The empirical investigation in Bangladesh found out that both in the long run and short run analyses population growth and economic growth is negatively correlated and that an increase in population will have a negative impact on the economy of Bangladesh, and it suggests that government should focus on family planning programs to overcome the negative consequence of rapid population growth (Shah et al., 2015)

According to (Chang et al., 2014), who used a time series data from (1871-2013) investigated an opposite result between the prior variables, and it suggested that serous economic concern of rapid population growth by spending family planning services, development of free media and liberal education in educational institutions will in time also help by encouraging a smaller family size, more emphasis should be given to technological development, which enables high labor productivity, per capital income and progress in living standards. Boserup (1965) found out population growth is an independent factor, which affect agricultural productivity rather than being affected by it. She disproves the Malthusian theory of diminishing marginal productivity of labor in the long run; behind here rationale of diminishing productivity of labor need not hold in the long run as a higher population may lead to a more efficient division of labor as well as to improved agricultural practice. The study concluded that soil fertility and minerals should not be assumed to be fixed and given by nature, rather it could be improved by technological outcomes and new way of cultivation system, which is likely to be the result of population pressure. Primitive societies along with higher population growth rates are more likely to experience economic development, provided that the necessary investment in agriculture is undertaken.

However, the study of Thirlwa (1993) obtained the complex relation between population growth and economic growth, with special attention of determining their causal relationship and revealed that population increase lowers per capita income. Hassen A,(2012) employed a Vector Error Correction (VEC) model to examine the impact of population growth on per capita income growth as a measure of economic growth in Ethiopia. The analytical framework he used was seems unique relative to others regarding to the multi feature of demographic characteristics. Therefore, the common practice of employing total population growth rate and GDP as a measure of growth is not likely to be important because of the fact that such crude measures might ignore the heterogeneity within the population in terms of age (dependent and independent) and economic activity (those in the labor force as employed versus unemployed or those economically inactive) among others. Accordingly, to overcome the problem of heterogeneity, he used population growth rate of dependents and employment growth rate as explanatory variable from the population aspect, as a result he found out that of the negative long run relationship between per capita income and population growth of dependents and a positive one between the former and growth rate of workers with bi-directional causality between both causes. That is rise in per capita income reduces the growth of dependent population and enhance that of workers, and vice versa. Conversely, slower growth of population or faster growth of workers raises per capita income. However, he was not clear with the bidirectional causality between variables, since he did not utilize the granger causality test mechanisms. Thuku G et al.,(2013) investigated the positive relationship between population growth and economic growth, and the study examined that if appropriate measures by the concerned body is undertaken to ensure that the economy grows at a higher rate than the population growth rate and it will attain the increase demands of services arising from the population growth is meet. Having a larger healthy and better educated workers help the nation to be sustainably developed. Open economies, flexible labor force, and modern institutions that can gain the confidence of the population and markets alike may help countries reap the potential benefits created by their demographic transition. Openness to trade can be driver of economic growth through to essential channels of technical progress and economies of scale, when there is an increase in population in the economy, it leads to technological innovation. Technological advance in turn promote productivity and economies of scale, hence, the national output. The main important thing what we should internalize here is that the causal relation or significant positive outcome of the two concepts will be realized if and only if there is the possibility to dream in the creation of human capital development through the help of well-equipped economic, social, political and demographic institutions to absorb the increase in populations.

Following the existing investigations and major paradigms from the theoretical and empirical point of view about the relation between population and economic growth, it is better to assess the methodological aspect from which researchers undertaken in the analyses of their study. Therefore, as far as the existing growth models are concerned, they are likely to be different in terms of the necessary assumptions as well as the overall methodological set up. For instance, Kassahun A., (2014) employed the standard neoclassical growth model approach as a general framework to analyze the impact of population growth to Ethiopian economic performance. 
The central concept of this model regarding to population growth and economic growth is that a higher rate of population growth lowers the steady state capita and output per worker and tends thereby to reduce the per capita growth rate for a given initial level of per capita output. The standard model dose not, however, considered the effect of per capita income and wage rates on population growth, the kinds of effect stressed by Malthus and also does not take in to account of the resources used up in chilled rearing (Barro R and Sala M., 1986). The implication is that the model considers population growth as exogenous variable, but it concludes it has an impact only in the long run or steady state condition of per capita income, hence, due to the exclusion of population growth as an endogenous factor of growth phenomenon, it is not advisable to utilize this model in its crude form, however it is possible to employ such model with the help of some possible modifications of the Solow-Swan model of economic growth. That is why Kassahun A., (2014) utilized this model as a tool of analyses, but his modification seems mechanistic in nature due to the crude nature of labor force he undertaken, irrespective of considering human capital as a proxy for development. In addition to this, he was not in a position to extract the existing empirical investigations as a supplementary tool of analyses.

Due to the limitation of the neoclassical theory of the Solow-Swan growth model of its exogenous assumption of technological advance and population growth, researchers utilized a Vector Auto Regression technique to solve the problem of the Solow-Swan model, because of the significance of the model with respect to investigate the causal relationship between population growth and economic growth, to determine whether population growth induces economic growth or economic growth induces population growth(Thuku et al., 2013, and Furuoka., 2010)

For the purpose of simplicity, the functional form of the model which is taken from most of the reviewed literature could be specified as:

$$
\begin{aligned}
& G D P t=c 1+\alpha 1 G D P t-1+. .+\alpha k G D P t-k+\beta 1 P O P t-1+\ldots+\beta k P O P t-k+\varepsilon 1 \ldots \ldots \text { (1) } \\
& P O P t=c 2+\alpha 1 P O P t-1+. .+\alpha k P O P t-k+\beta 1 G D P t-1+\ldots+\beta k G D P t-k+\varepsilon 2
\end{aligned}
$$

where $\mathrm{c} 1$ and $\mathrm{c} 2$ are constants; $\alpha 1 \ldots \ldots . . \alpha \mathrm{k}$ and $\beta 1 \ldots \ldots \beta \mathrm{k}$ are slope coefficients

Here, the variable population growth is considered to be both an endogenous and exogenous variable by refining the neo classical model of growth. Despite the applicability of this model, many researchers who employ this model (VAR) on this ground ignores the inclusion of other aggregate explanatory variables which are expected to affect economic growth, in other words, the goodness of fit and specification test issue of their model would be questionable. In addition to the above preposition, as we know, in time series analyses, time has a very significant factor on the value of variables undertaken within a given specific model as well as its respective stochastic terms. So that here, growth of GDP and population growth as an endogenous variable is expressed as a function of each other and their own lag explanatory variables. Therefore, we should suspect the presence of correlation among explanatory variables, but they are not in a position to test such a problem and simply accept the larger amount of coefficient of determination $\left(\mathrm{R}^{2}\right)$ as an indication of the very good explanatory power of the model (Furuoka., 2010, Thuku G et al., 2013, Ahmad R., and Ahamd K., 2016, Nwosu et al., 2014).

Furthermore, to investigate the long run relationship between population growth and economic growth among different countries an Augmented Dickey Fuller co-integration test is utilized and a unit root stationery test is also undertaken to check whether the mean value and variance of the error term are constant (time invariant) throughout the model or not. In a time series analyses, both the short run and long run relationship between variables should be determined, in case, an application of Granger causality with the help of Vector Error Correction (VECM) mechanism relative to the standard one is advisable to address the extent at which the short run disequilibrium among variables are running towards its long run equilibrium (Furuoka., 2010).

\section{Conclusion}

In conclusion, as we can understand from the theoretical argument and empirical investigations of the various written literatures about the relation between population growth and economic growth, neither of the existing arguments out weights the other. In addition, the nature of causation (whether population growth induces economic growth or economic growth or development induces population growth) between the two variables receive the attention of many scholars. As a result, some of the findings found out the un-directional causation between the two and others also reveal a bi-directional causation by utilizing the Granger Causality test technique. Thus, as far as the case in Ethiopia is concerned, in the short run, population pressure has an adverse effect on economic growth, but in the long run population growth stimulates economic growth. On the other hand, Hassen (2012) find out an inverse bidirectional causality and direct bidirectional causality between number of dependents and working age population with the associated economic growth respectively. In other words, when there is higher number of inactive population in the economy, then economic growth declines both in the short run and in the long run, and an increase in working age population fosters economic growth both in the short run and in the long run and vice versa is true in the reverse causation.

Accordingly, relative to the developed world as many empirical and theoretical arguments realized, population growth hampers the growth and development of least developing countries, as a result, Ethiopia is not unique to the region. Thus, the issue of population growth in line with economic growth and development should 
be a primary concern of policy and strategy. The central point here is that speaking about the crude or mechanistic nature of population pressure as a determinant of growth is somewhat unrealistic. It implies that the qualitative aspect of human development (as the endogenous growth model reveals) for instance, educational quality, proper health service, establishment of well-designed institutions from the social, economic political and cultural aspect of life matters. Moreover, the mere nature of the nexus between population growth and the economy could not significantly determine causation rather initial condition, technology, age structure, policy, culture and religion and other qualitative variables matters.

\section{Recommendation}

To do get the fruits of population growth, the issue of population growth should be included in the process of development planning, which is endogenous to the growth process. A well-managed population expansion may ensure that both the population and the economy is complementing each other, without such a concern, the country becomes underdeveloped forever, results from resource exploitation, unemployment, insecurity and diseconomies of scale. Policies should be designed to improve human capital or skill and quality than quantity to improve productivity at the margin. The situation of brain drain should be undertaken to minimize externality which undermines the advantage of population growth/ surplus labor force and human capital domestically.

\section{Reference}

Admassu T. (2015) . Population Change and Economic; case studies and reflection on the Ethiopian Demographic Transition. Developing Country Studies. Wollega University, Nekemt, Ethiopia.

Ahmad R,. and Ahmad K. (2016). Impact of Population on Economic Growth: A Case Study of Pakistan. Bulletin of Business and Economics, 5(3), 162-176. 162.

Ali S., Ali A., and Amin A. (2013). The Impact of Population Growth on Economic Development in Pakistan. Meddle East Journal of Scintific Research 18(4): 483-491, 2013

Barro R, and Sala M. (1986).Economic Growth, Second edition, Cambride, Massachusetts, London, England.

Birdsall N. (1988) .Economic Approach to Population Growth in Chenery H, Srinivasan T (1988). Hand book of Development Economics, Vol.1.

Bloom D, et al. (2001) . "Economic Growth and the Demographic Transition", NBER working paper series ,6268.

Bloom D., and Freeman R. (1998). Economic Development and the Timing and Component of Population Growth; Journal of Policy Modeling 10(1), 57-81

Boserup E . (1965): The Conditions of Agricultural Process, Allen and Uriwing, London.

Bucci A. (2003): " Population Growth in a model of Economic Growth with Human Capital Accomulation", University of Milan, Milan.

Chang T., Chu H., Deale F., Gupta R. (2014). The Relationship Between Population Growth and Economic Growth Over 1870-2013: Evidence from a Bootstrapped Panel Granger Causality test, no 201431.

Furuoka F. (2010). Population Growth and Economic Development; Emperical Evidence from the Philipnes.

Hassen A. (2012). Demographic Changes and Economic Development; Application of the Vector Error Correction Model to the case of Ethiopia. Journal of Economics and International Finance, Vol. 4(10), pp.236-251.

Kasshahun A. (2014) .Impact of Population Growth on Ethiopian Economic Performance, Addis Ababa University, School of Graduate Studies.

Malthus T. (1798). An Essay on the Principles of Population, ( Cambridge: Cambridge University press).

Mankiw G., Roomer D., and Weil P. (1992). A Contribution to the Emperics of Economic Growth, Quarterly Journal of Economics.

Martin P. (2009). “ Demographic and Economic Trends: Implications for International Mobility”. United Nation Development Program Human Development Report. Research Paper 2009/17.

Nwosu C., Dike A., and Okwara K. (2014): The Effect of Population Growth on Economic Growth in Nigeria. The International Journal of Engeenering and Science.vol,3,no, 11, 07-18.

Ohadike P.(1996).The African Population Growth and Development Conundrum. Health Transition Review, supplement to Volum, 6, 1996, 325-344.

Ozgur M., and Savas B. (2009).Temporal Causality Between Population and Income in Turky:, an ardl bounds testing approach, Aksaray University Iktisadi Idari Bilimler Fakultesi Dergisi, 1(1), 162-176.

Quang M. (2012). Population and Economic Growth in Developing Countries. International Journal of Accadamic Research in Business and Social Science,ol, 2,no 1.ISSN:2222-6990.

Shah .,Sargani G.,Ali A., and Siraj, W. The Effect of Increase in Population on Economic Growth of Bangladsh.

Simon J. (1977).The Economics of Population Growth Princeton University Press: Princeton New Jersey.

Tarliyus E, lnuwa, M. Peter A. (2015) . Impact of Population Growth on Economic Growth in Nigeria,LOSR, Journal of Humanities and Social Science. Vol.20, Isssu, 4, 2279-0845.

Thirlwal, A .(1993). "Growth and Development with special reference to Developing Economies". University of Kent at Canterury, $5^{\text {th }}$ edition. PP.143-155. 
Thuk G, Paul G, and Almadi O. (2013).The Impact of Population Change on Economic Growth in Kenya . International Journal of Economics and Management Science, vol . 2, no. 6,2013, pp, 43-60

Todaro M. (1994) .Economic Development, New Work, London.

Tsegaye T. (2011). The Elephant in the Room: Population and Economic Growth Discourse in Ethiopia.

Yaoanudjo E. (2015).The Population Economies Nexus; new evidence from Ghana

Zelalem G . (2016). Effect of Population growth on the Economic growth of Ethiopia. 